\section{Prevalence of Mycobacterium avium subsp. paratuberculosis in milk and dairy cattle in Southern Italy: preliminary results}

\author{
Giacomo Marchetti, ${ }^{1}$ Matteo Ricchi, ${ }^{2}$ \\ Andrea Serraino, ${ }^{1}$ Federica Giacometti, \\ Elena Bonfante, ${ }^{1}$ Norma Arrigoni ${ }^{2}$ \\ 'Dipartimento di Scienze Mediche \\ Veterinarie, Alma Mater Studiorum - \\ Università di Bologna, Ozzano dell'Emilia \\ (BO); '2 Istituto Zooprofilattico \\ Sperimentale della Lombardia ed Emilia \\ Romagna, Sezione di Piacenza, Gariga di \\ Podenzano (PC), Italy
}

\section{Abstract}

Paratuberculosis affects all ruminants worldwide. Mycobacterium avium subsp. paratuberculosis (MAP) could have a role in human diseases like Crohn's. Some extra European Union (EU) countries request importation of MAP-free products. Italy has not yet actualised a control programme and the diffusion of the infection is still unknown in Southern Italy. The aim of this study was to evaluate the prevalence of the infection in five regions of Southern Italy. Bulk tank milk and in-line milk filters were sampled in 780 dairy cattle herds and respectively analysed by ELISA and real time-polymerase chain reaction (PCR). One hundred and 55 out of 780 herds (19.9\%) were found positive by ELISA and/or real time PCR. Individual milk samples were then collected from all the producing animals of positive herds and from a selection of negative herds. The estimated prevalence varies from region to region between 2.8 and $5.5 \%$. Our results indicate that the disease is widespread in the five regions. The observed prevalence could be underestimated.

\section{Introduction}

Mycobacterium avium subsp. paratuberculosis (MAP) is the etiological agent of paratuberculosis, also known as Johne's disease (JD), a chronic and progressive granulomatous enteritis affecting ruminants, especially dairy cattle, and a variety of domestic and wildlife species (Beard et al., 2001; Chiodini et al., 1984; Kennedy and Benedictus, 2001). In cattle the disease is characterized by chronic diarrhea, weight loss, decreased milk production, and often leads to death (Ayele et al., 2001; Chacon et al., 2004), causing important economic losses in dairy and beef industry.

The zoonotic potential of MAP has been debated for almost a century due to clinical and pathological similarities between ruminants JD and humans Crohn's disease (CD) and in last years the role of MAP as a cause of human type I diabetes, Hashimoto's thyroiditis and multiple sclerosis has been hypothesized (Cossu et al., 2013; Shanahan and 0'Mahony, 2005; Sisto et al., 2010). Patients with CD have similar symptoms to those of JD and evidence of MAP in the gut has been found in $52-92 \%$ of Crohn's patients using polymerase chain reaction (PCR) (Autschbach et al., 2005; Bull et al., 2003). The transmission of MAP to humans most likely occurs via contaminated milk and milk products (Gill et al., 2011).

MAP can survive low-temperature holding $\left(63^{\circ} \mathrm{C}\right.$ for $\left.30 \mathrm{~min}\right)$ and high temperature-short time (HTST) $\left(72^{\circ} \mathrm{C}\right.$ for $\left.15 \mathrm{sec}\right)$ pasteurization (Grant et al., 1996; Grant, 2006; Millar et al., 1996; Sung and Collins, 1998; Van Brandt et al., 2011): some surveys showed the presence of MAP in commercially pasteurized milk purchased at retail (Carvalho et al., 2012; Ellingson et al., 2005; Grant et al., 2002; Shankar et al., 2010).

Available evidences of the involvement of MAP in human diseases have been inconclusive, but still some extra EU countries, like China and India, are beginning to request certifications to ensure importation of MAP-free products.

The prevalence of MAP infection is still unknown in many regions of the world and there is the need to study the spread of the disease for many reasons: the economic losses; the likelihood of the zoonotic potential of MAP; its capability of surviving the pasteurization; the increase of the request of MAP-free animals and products.

Many countries have developed voluntary or mandatory strategies aimed to eradicate or control the disease. In Italy, during the year 2012, national institutions (Arrigoni, 2012) have developed a voluntary national plan of probable forthcoming emission with the purposes of supporting exportations, decreasing the diffusion of the infection, creating positive conditions for a conscious commerce of animals and their products. Actually, the national plan is still in process and the knowledge on the diffusion of MAP infection in Italian herds is fragmented and incomplete; several studies have investigated MAP diffusion in Northern and Central Italy (Cenci-Goga et al., 2010; Lillini et al., 2005; Pozzato et al., 2011), but the only information on the presence of MAP in Southern Italy date back to 1989 (Vesco et al., 1990) and no data on the prevalence of the disease in dairy cattle herds are available.

In this study was conducted a survey on 780 dairy cattle herds in five different regions of
Correspondence: Andrea Serraino, Dipartimento di Scienze Mediche Veterinarie, Alma Mater Studiorum - Università di Bologna, via Tolara di Sopra 50, 40064 Ozzano Emilia (B0), Italy. Tel.+39.051.2097332 - Fax: +39.051.2097346. E-mail: andrea.serraino@unibo.it

Key words: Paratuberculosis, Mycobacterium avium, Dairy, Herds, Italy.

Received for publication: 26 April 2013. Revision received: 29 May 2013.

Accepted for publication: 30 May 2013.

Conflict of interests: the authors declare no potential conflict of interests.

This work is licensed under a Creative Commons Attribution 3.0 License (by-nc 3.0).

(C) Copyright G. Marchetti et al., 2013

Licensee PAGEPress, Italy

Italian Journal of Food Safety 2013; 2:e35

doi:10.4081/ijfs.2013.e35

Southern Italy. The aim of the study was to evaluate the prevalence of paratuberculosis at herd and within-herd level in order to estimate the prevalence of the disease in these regions where the situation was still unknown.

\section{Materials and Methods}

\section{Collection of samples}

In this study, 780 farms located in Southern Italy were considered. Bulk tank milk (BTM) and in-line milk filter (ILMF) samples were requested to farmers. Samples were collected in sterile Falcon tubes and immediately frozen at $-20^{\circ} \mathrm{C}$ and shipped to the laboratory within 15 days from sampling. BTM samples were obtained from 778 herds and ILMF were received from 496 herds. Many little herds did not require the use of in line milk filters, therefore only BTM were analysed in the study (Table 1). Overall the number of dairy cattle herds sampled for BTM and/or ILMF was 780 . To ensure a collection of samples representing all the producing animals of each herd, a second sampling of BTM and ILMF was requested to farmers after six months from the first sampling. Details on the number of BTM and ILMF collected in the first and in the second sampling are reported in Table 1 . The complete sampling was performed in 410 out of 780 farms (52.5\%).

In order to estimate the within-herd prevalence of MAP infection, individual milk samples from all the lactating cows were collected from 115 of the 155 (74.2\%) positive herds and from 35 negative herds Individual milk samples were collected six months to one year later 
than BTM and ILFM previously collected samples. In total 12189 individual milk samples were analysed.

\section{ELISA method}

BTM and individual milk samples were tested for antibodies against MAP using a commercially available ELISA (ID Screen ${ }^{\circledR}$ Paratuberculosis indirect confirmation test; IDVET, Montpellier, France), according to the manufacturer's instruction.

\section{DNA extraction}

ILMF were cut into small pieces (about 15 $\mathrm{cm}^{2}$ ), put in filtered Stomacher bags with 100 $\mathrm{mL}$ of Phosphate Buffered Saline added with Tween 20 0.05\% (PBS Tween 20) and homogenized at $300 \mathrm{rpm}$ for $2 \mathrm{~min}$ in a Stomacher 400 Circulator (International PBI, Milan, Italy). Fifty $\mathrm{mL}$ of homogenate were collected into a falcon tube and centrifuged at $2500 \mathrm{xg}$ for 15 min. The obtained pellet was resuspended in 1 $\mathrm{mL}$ of PBS Tween 20, vortexed and transferred into a $1.5 \mathrm{~mL}$ eppendorf tube.

Five $\mu \mathrm{L}$ of MyOne Tosylactivated Dynabeads (Life Technologies, Milan, Italy) coated with aMp3 peptide (NYVIHDVPRHPA) and $5 \mu \mathrm{L}$ of MyOne Tosylactivated Dynabeads coated with aMptD peptide (GHNHHHQHHRPQ) (Research Biochemicals, Cambridge, UK) were added to the suspensions obtained by ILMF. The samples were subjected to continuous rotation on a Stuart Rotator SRT6 (SigmaAldrich, St. Louis, MO, USA) mixer for $30 \mathrm{~min}$ at $30 \mathrm{rpm}$ at room temperature. The samples were then subjected to magnetic separation for 10 minutes and washed two times with $1 \mathrm{~mL}$ PBS Tween 20. The beads were resuspended in $300 \mu \mathrm{L}$ of PBS Tween 20, $200 \mu \mathrm{L}$ of sterile water, added of $300 \mathrm{mg}$ of SIGMA glass beads (150-212 $\mu \mathrm{m}$ diameter) and subjected to bead beating in Tissue Lyser for $10 \mathrm{~min}$ at 30 Hertz.

Two-hundred $\mu \mathrm{L}$ of surnatant were collected in a new $1.5 \mathrm{~mL}$ Eppendorf tube and samples were then subjected to DNA extraction with a commercially available DNA extraction kit following the manufacturer's instructions (DNeasy Blood and Tissue Kit; QIAGEN, Milan, Italy).

\section{Real-time polymerase chain reaction}

Real-time PCR was performed targeting IS900 sequence with primers and probe already described (Ricchi et al. 2009). The amplification reactions were performed in duplicate for each sample using a Step0ne Plus System (Life Technologies) in $20 \mu \mathrm{L}$ of master mix containing $300 \mathrm{nM}$ of each primer, and $6 \mathrm{nM}$ of the probe. An internal positive control (Life Technologies) was also used. PCR reactions were performed at the following conditions: 40 cycles of denaturation for $15 \mathrm{sec}$ at $95^{\circ} \mathrm{C}$ and annealing/elongation for $60 \mathrm{sec}$ at $60^{\circ} \mathrm{C}$. The limit of detection of this method was estimated to be $10-20 \mathrm{CFU} /$ filter. The limit of detection was estimated by spiking MAP-free ILMF with ten-fold diluitions of one ATCC 19698 strain and one field strain. ILMF were then tested with to the previously described DNA extraction and real time PCR, comparing the results with culture on Herrold Egg Yolk Medium (data not shown). The efficiencies of the reactions were evaluated according to Pfaffl (2001).

\section{Results}

A total of 155 of 780 herds (19.9\%) were found positive on BTM and/or on ILMF. In particular, 104/778 herds (13.4\%) were positive by ELISA on BTM, 92/496 herds (18.5\%) were positive by RT-PCR on ILMF and 41/494 (8.3\%) were positive on both BTM and ILMF. In four of the five tested regions the percentage of positive herds varied from 20.5 to $23.4 \%$ and in one region we found positive $12.8 \%$ of dairy herds. The within-herd estimated prevalence (EP) varied from region to region from a minimum of $2.8 \%$ to a maximum of $5.5 \%$. In total 649 (5.3\%) out of 12,189 individual milk samples resulted positive. Details on the within-herd prevalence of the 115 herds resulted positive to BTM and/or ILMF analysis and of the 35 negative farms tested for individual samples which are reported in Table 2.

\section{Discussion}

In this study we analyzed BTM and/or ILMF from 780 dairy herds in five regions of Southern Italy. Real time PCR on ILMF allowed to detect $18.5 \%$ positive dairy herds versus $13.4 \%$ detected by ELISA BTM analysis.

The herd level EP showed similar distributions between four regions (20.5-23.4\%). Only one region showed a remarkable lower herd level EP value (12.8\%); this can be due to the lower number of ILMF samples collected in this region (only from $26.2 \%$ of herds, in contrast with $49.5-88.5 \%$ of herds from other regions). Two main factors may be the cause of the lower prevalence: i) the lower capability demonstrated by BTM analysis in detecting positive herds and ii) the fact that the absence ILMF is usually associated to herds with low numbers of milking cows, which are reported to be at lower risk for paratuberculosis infection (Collins et al., 1994; Wells and Wagner, 2000).

In the surveyed five regions, the EP of paratuberculosis at herd level seems to be remarkably lower than in other surveyed italian regions. In the region of Latium the prevalence was estimated to be $42 \%$ (Lillini et al., 2005). In the regions of Lombardy and Veneto the EP resulted, respectively, 48 and $65 \%$ (Pozzato et al., 2011). The European (Nielsen and Toft, 2009) and US (APHIS, 2008) prevalence estimations are $>50 \%$. The difference can be due to the use of different tests and to the procedure of selection of herds. For exam-

Table 1. Number of bulk tank milk, in-line milk filters samples, and sampled farms.

$\begin{array}{lccccc} & \text { First sampling } & \text { Second sampling } & \text { Total samples } & \text { Sampled farms (n) } & \begin{array}{c}\text { Farms where the complete } \\ \text { sampling plan was performed (n) }\end{array} \\ \text { BTM } & 730 & 687 & 1417 & 778 & 410 \\ \text { ILMF } & 463 & 448 & 911 & 496 & 410\end{array}$

BTM, bulk tank milk; ILMF, in-line milk filter.

Table 2. Within-herd estimated prevalence in farms resulted positive or negative to bulk tank milk and in-line milk filters.

\begin{tabular}{|c|c|c|c|c|c|c|}
\hline \multirow{2}{*}{\multicolumn{2}{|c|}{ Sampled farms (n) }} & \multicolumn{3}{|c|}{ Within-herd EP (\%) } & \multirow{2}{*}{$\begin{array}{l}\text { Total sampled } \\
\text { animals (n) }\end{array}$} & \multirow{2}{*}{$\begin{array}{l}\text { Positive } \\
\text { animals (n) }\end{array}$} \\
\hline & & Minimum & Mean & Maximum & & \\
\hline BTM and ILMF negative & 35 & 0 & $1.94 \pm 0.02^{*}$ & 12.7 & 3184 & 77 \\
\hline BTM or ILMF positive & 115 & 0 & $6.10 \pm 0.02 *$ & 26.1 & 9362 & 572 \\
\hline
\end{tabular}

EP, estimated prevalence; BTM, bulk tank milk; ILMF, in-line milk filter. *Values are presented as \pm standard deviation. 
ple, the prevalence of MAP infection in Lombardy and Veneto regions (Pozzato et al., 2011) was estimated by sampling the serum of all the animals older than 12 months of age in a group of randomly selected herds. In our study were sampled individual milk of 115 dairy farms resulted positive to BTM or ILMF screening test. Testing the 35 farms which resulted negative to the screening tests showed that 19 herds resulted with at least one infected animal and thus the number of infected herds and the EP was underestimated. One additional cause for the lower prevalence detected could be the largeness of the herds which is usually lower in southern Italy than in Northern Italy.

On the contrary, the mean observed withinherd EP in four regions (4.45\%) is comparable to the one observed in Veneto region (4.15.9\%) (Pozzato et al., 2011) and higher to the ones observed in Lombardy (2.6\%) (Pozzato et al., 2011) and in Latium (2\%) (Lillini et al., 2005). However in the comparison of these data two main aspects must be taken in account: first of all, the majority of animals tested in our study were sampled from herds tested positive to the analysis on BTM and/or ILMF. In fact, we tested all the lactating animals of 115 positive herds and only of 35 negative herds. This can lead to overestimate the mean within-herd EP. The other aspect is that we analyzed individual milk samples using a commercial ELISA kit (IDVet), which has a sensitivity of $60 \%$ (Lavers et al., 2012). In the other studies, ELISA was performed on serum with two different commercial kits (Pourquier and IDEXX), which sensitivities varied from study to study (Nielsen and Toft, 2008) and in the study by Pozzato et al. (2011) were assumed to be, respectively, 15 and $9 \%$. Additionally, the prevalence of infected animals detected in our study was evaluated in lactating cows, thus in animals that are at least 22 month-old.

The screening sampling plan tested may be a useful tool to detect farms with higher intra herd prevalence and with higher risk to produce milk contaminated by MAP in comparison to sampling serum of animals of all the animals older than 12 months as performed in previous studies (Pozzato et al., 2011). Sampling the serum requires time, money and employees. Analyzing BTM and ILMF samples is faster and cheaper. Although it probably leads to underestimate the true prevalence of MAP, the screening sampling plan performed detected as positive dairy herds with higher within-herd prevalence $(6.10 \pm 0.04 \%)$, while herds with lower within-herd prevalence resulted negative $(1.94 \pm 0.02 \%)$.

By the way, the lack of sensitivity of the screening sampling plan can be overcome by repeating the tests. In fact, 55 of the 115 positive herds $(47.8 \%)$ resulted negative to the first sampling and positive after six month. This trend is probably due to the fluctuation of the concentration of antibodies (Gilardoni $e t$ al., 2012; Sweeney et al., 2006) and the intermittent shedding of MAP with milk and faeces (Gill et al., 2011), as well as the turnover of milking cows.

\section{Conclusions}

Our study demonstrates that MAP is widespread in dairy cattle herds of Southern Italy. Our approach could lead to underestimate the true prevalence, but repetitions of the sampling in time can overcome the lack of sensitivity and the method is a fast and cheap alternative to screen a great number of dairy cattle herds in a short time. The study is still in progress and our data should be analysed with a Bayesian model (Branscum et al., 2004), in order to obtain the true prevalence of infection taking into account the $\mathrm{EP}$, the variability in the accuracy of diagnostic tests and the uncertainty about the prevalence.

\section{References}

APHIS, 2008. Johne's Disease on U.S. Dairies, 1991-2007 info sheet. Animal and Plant Health Inspection Service ed., Washington, USA. Available from: http:/ /www.aphis.usda.gov/animal_health/nahm s/dairy/downloads/dairy07/Dairy07_is_Joh nes.pdf

Arrigoni N, 2012. [Paratubercolosi: focus sulle novita nazionali ed internazionali]. [Article in Italian]. Available from: http://www.ausl.fe.it/azienda/dipartimenti/sanita-pubblica/servizio-veterinario/ corsi-ecm/corso-paratubercolosi-11-102012/norma-arrigoni.-paratbc-parte-3novita-nazionali-ed-internazionali

Autschbach F, Eisold S, Hinz U, Zinser S, Linnebacher M, Giese T, Loffler T, Buchler MW, Schmidt J, 2005. High prevalence of Mycobacterium avium subspecies paratuberculosis IS900 DNA in gut tissues from individuals with Crohn's disease. Gut 54:944-9.

Ayele WY, Machackova M, Pavlik I, 2001. The transmission and impact of paratuberculosis infection in domestic and wild ruminants. Vet Med-Czech 46:205-24.

Beard PM, Daniels MJ, Henderson D, Pirie A, Rudge K, Buxton D, Rhind S, Greig A, Hutchings MR, McKendrick I, Stevenson K, Sharp JM, 2001. Paratuberculosis infection of nonruminant wildlife in Scotland. $\mathrm{J}$ Clin Microbiol 39:1517-21.

Branscum AJ, Gardner IA, Johnson WO, 2004.
Bayesian modeling of animal- and herdlevel prevalences. Prev Vet Med 66:101-12.

Bull TJ, McMinn EJ, Sidi-Boumedine K, Skull A, Durkin D, Neild P, Rhodes G, Puckup R, Hermon-Taylor J, 2003. Detection and verification of Mycobacterium avium subsp. paratuberculosis in fresh ileocolonic mucosal biopsy specimens from individuals with and without Crohn's disease. J Clin Microbiol 41:2915-23.

Carvalho IA, Pietralonga PAG, Schwarz DGG, Faria ACS, Moreira MAS, 2012. Short communication: recovery of viable Mycobacterium avium subspecies paratuberculosis from retail pasteurized whole milk in Brazil. J Dairy Sci 95:6946-8.

Cenci-Goga BT, Vescera F, Paolotto P, McCrindle CM, Roberti U, 2010. Seroprevalence of Mycobacterium avium subspecies paratuberculosis in cows in Umbria, Italy. Vet Rec 167:577-8.

Chacon 0, Bermudez LE, Barletta RG, 2004. Johne's disease, inflammatory bowel disease, and Mycobacterium paratuberculosis. Annu Rev Microbiol 58:329-63.

Chiodini RJ, Van Kruiningen HJ, Merkal RS, 1984. Ruminant paratuberculosis (Johne's disease): the current status and future prospects. Cornell Vet 74:218-62.

Collins MT, Sockett DC, Goodger WJ, Conrad TA, Thomas CB, Carr DJ, 1994. Herd prevalence and geographic distribution of, and risk factors for, bovine paratuberculosis in Wisconsin. J Am Vet Med Assoc 204:63641.

Cossu D, Masala S, Cocco E, Paccagnini D, Tranquilli S, Frau J, Marrosu MG, Sechi LA, 2013. Association of Mycobacterium avium subsp. paratuberculosis and SLC11A1 polymorphisms in Sardinian multiple sclerosis patients. J Infect Dev Ctries 7:203-7.

Ellingson JLE, Koziczkowski JJ, Anderson JL, 2005. Detection of viable Mycobacterium avium subsp. paratuberculosis in retail pasteurized whole milk by two culture methods and PCR. J Food Protect 68:96672 .

Gilardoni LR, Paolicchi FA, Mundo SL, 2012. Bovine paratuberculosis: a review of the advantages and disadvantages of different diagnostic tests. Rev Argent Microbiol 44:201-15.

Gill C0, Saucier L, Meadus WJ, 2011. Mycobacterium avium subsp. paratuberculosis in dairy products, meat, and drinking water. J Food Protect 74:480-99.

Grant IR, 2006. Mycobacterium avium ssp. paratuberculosis in foods: current evidence and potential consequences. Int J Dairy Technol 59:112-7.

Grant IR, Ball HJ, Neill SD, Rowe MT, 1996. Inactivation of Mycobacterium paratuberculosis in cows' milk at pasteurization 
temperatures. Appl Environ Microb 62:6316.

Grant IR, Ball HJ, Rowe MT, 2002. Incidence of Mycobacterium avium subsp. paratuberculosis in bulk raw and commercially pasteurized cow's milk from approved dairy processing establishments in the United Kingdom. Appl Environ Microb 68:2428-35.

Kennedy DJ, Benedictus G, 2001. Control of Mycobacterium avium subsp. paratuberculosis infection in agricultural species. Rev Sci Tech OIE 20:151-79.

Lavers C, Keefe G, McKenna S, Chaffer M, 2012. Evaluation of three commercial ELISA kits for the determination of herd status for Johne's disease on Atlantic Canadian dairy farms. Available from: http://www.paratuberculosis.info/web/images/proc11/050.pdf

Lillini E, Bitonti G, Gamberale F, Cersini A, 2005. Prevalence of bovine paratuberculosis in the Latium region (Italy). Available from: http://www.paratuberculosis.info/ web/images/stories/pdfs/197

Millar D, Ford J, Sanderson J, Withey S, Tizard M, Doran T, Hermon Taylor J, 1996. IS900 PCR to detect Mycobacterium paratuberculosis in retail supplies of whole pasteurized cows' milk in England and Wales. Appl Environ Microb 62:3446-52.

Nielsen SS, Toft N, 2008. Ante mortem diagnosis of paratuberculosis: a review of accuracies of ELISA, interferon-gamma assay and faecal culture techniques. Vet Microbiol
129:217-35.

Nielsen SS, Toft N, 2009. A review of prevalences of paratuberculosis in farmed animals in Europe. Prev Vet Med 88:1-14.

Pfaffl MW, 2001. A new mathematical model for relative quantification in real-time RTPCR. Nucleic Acids Res 29:e45.

Pozzato N, Capello K, Comin A, Toft N, Nielsen SS, Vicenzoni G, Arrigoni N, 2011. Prevalence of paratuberculosis infection in dairy cattle in Northern Italy. Prev Vet Med 102:83-6.

Ricchi M, Taddei R, Barbieri I, Belletti GL, Pacciarini ML, Arrigoni N, 2009. Typing of Mycobacterium avium subsp. paratuberculosis (MAP) strains isolated from different Italian regions by four Variable-Number Tandem Repeat (VNTR) methods alone or in association. Available from: http://www.paratuberculosis.info/web/images/stories/pdfs/314.pdf

Shanahan F, O'Mahony J. 2005. The mycobacteria story in Crohn's disease. Am J Gastroenterol 100:1537-8.

Shankar H, Singh SV, Singh PK, Singh AV, Sohal JS, Greenstein RJ, 2010. Presence, characterization, and genotype profiles of Mycobacterium avium subspecies paratuberculosis from unpasteurized individual and pooled milk, commercial pasteurized milk, and milk products in India by culture, PCR, and PCR-REA methods. Int J Infect Dis 14:e121-6.

Sisto M, Cucci L, D’Amore M, Dow TC, Mitolo V,
Lisi S, 2010. Proposing a relationship between Mycobacterium avium subspecies paratuberculosis infection and Hashimoto's thyroiditis. Scand J Infect Dis 42:787-90.

Sung N, Collins MT, 1998. Thermal tolerance of Mycobacterium paratuberculosis. Appl Environ Microb 64:999-1005.

Sweeney RW, Whitlock RH, McAdams S, Fyock T, 2006. Longitudinal study of ELISA seroreactivity to Mycobacterium avium subsp. paratuberculosis in infected cattle and culture-negative herd mates. J Vet Diagn Invest 18:2-6.

Van Brandt L, Van der Plancken I, De Block J, Vlaemynck G, Van Coillie E, Herman L, Hendrickx M, 2011. Adequacy of current pasteurization standards to inactivate Mycobacterium paratuberculosis in milk and phosphate buffer. Int Dairy J 21:295304.

Vesco G, Vitale F, Prato F, Caracappa S, 1990. [Diffusione ed isolamento di M. paratuberculosis di bovini infetti in Sicilia]. In: [Atti della società italiana di buiatria]. [Proc. in Italian]. Vol XXII, pp 553-7.

Wells SJ, Wagner BA, 2000. Herd-level risk factors for infection with Mycobacterium paratuberculosis in US dairies and association between familiarity of the herd manager with the disease or prior diagnosis of the disease in that herd and use of preventive measures. J Am Vet Med Assoc 216:1450-7. 